\title{
AUTHOR STANCE IN ACADEMIC WRITING: A CORPUS-BASED STUDY ON EPISTEMIC VERBS
}

\author{
Reyhan Ağçam \\ Kahramanmaraş Sütçü İmam University, Turkey \\ Phone: +903442801941, E-Mail: reyhanagcam@gmail.com
}

\begin{abstract}
Stance refers to the lexical and grammatical expression of attitudes, feelings, judgments, or commitment concerning the propositional content of a message (Biber and Finegan, 1989). The present study is focused on epistemic verbs used in conveying author's stance in Academic English. Being corpus-based in design, it investigates whether native and non-native speakers of English significantly differ with respect to the use of these items through the Contrastive Interlanguage Analysis (Granger, 1996) of doctoral dissertations written by native, Turkish-speaking and Spanish-speaking speakers of English. Findings of the study have indicated that Turkish-speaking group tends to be more confident and the native and Spanish-speaking groups are relatively more cautious in their academic writing. The study ends with a couple of reasons for these particular findings and a few instructional suggestions for academic writing.
\end{abstract}

Key words: stance, epistemic verb, Contrastive Interlanguage Analysis

\section{INTRODUCTION}

Taking increasing attention in academic writing stance have been identified and discussed by leading figures in the field since the late 1980s. It refers to the lexical and grammatical expression of attitudes, feelings, judgments, or commitment concerning the propositional content of a message (Biber and Finegan, 1989). According to Faircough (1992, p. 160) it is the point of intersection in discourse between the ideational and interpersonal functions of language. Hunston and Thompson (2000) use the term "evaluation" for "stance" and assign three basic functions to it: "to express the writer's opinion, and in doing so to reflect the value system of that person and their community", "to construct and maintain relations between the writer and the reader", and "to organize the discourse". In line with these definitions, Stubbs (1986) posits that academic texts inevitably contain the author's attitude. Salager-Meyer (1997) calls our attention to the result of various research conducted in various disciplines that rhetorical objectives in academic discourse are realized as hedges, which she defines as "mostly verbal and adverbial expressions such as can, perhaps, may, suggest, which deals with degree of probability" and maintains that they can be considered as "the interactive elements which serve as a bridge between the propositional information in the text and the writer's factual interpretation". She also advocates that they are used "to reflect not only fundamental characteristics of modern science (scepticism, uncertainty and doubt), but also the true 
state of the writer's understanding and state of knowledge." As one of the semantic categories identified by Conrad and Biber (2000), epistemic stance refers to the degree of certainty or reliability of a writer's proposition and it is conveyed through certainty and likelihood devices proposed by Biber (2006).

Table 1 Epistemic stance devices (Adapted from Biber, 2006, p. 105-113)

\begin{tabular}{|c|c|}
\hline$\overline{\text { ESDs }}$ & E.g. \\
\hline Adjective + that-clause & $\begin{array}{l}\text { It is also clear[that their cordiality and mutual respect was } \\
\text { enhanced rather than hampered by the geographical distance } \\
\text { between them]. }\end{array}$ \\
\hline Adjective + to-clause & $\begin{array}{l}\text { It is still scarcely possible [to distinguish between an identity, } \\
\text { securing core of tradition and a periphery open to revision]. }\end{array}$ \\
\hline Adverb & $\begin{array}{l}\text { But, what I really have to do though is to keep the total time } \\
\text { frame for each person, almost exact, to fifteen minutes. }\end{array}$ \\
\hline Noun + that-clause & $\begin{array}{l}\text { I started out with the assumption [that consciousness is } \\
\text { complete with the ontological proof]. }\end{array}$ \\
\hline Verb + that-clause & $\begin{array}{l}\text { We recognize [that it's a real error [unclear words] because he } \\
\text { pursues the ideal out of this world]. }\end{array}$ \\
\hline Verb + to-clause & $\begin{array}{l}\text { Many Deep Ecologists of today seem [to define human beings } \\
\text { as an alien presence on the earth]. }\end{array}$ \\
\hline
\end{tabular}

Hyland (1994, p. 239) argues that epistemic devices are significant characteristics of academic writing by allowing writers to express their uncertainty concerning the factuality of their statements or to indicate deference to their ideas. A significant number of studies have been carried out on the use of stance devices so far (Ventola and Maureanen, 1990; Gosden, 1990; Hyland and Milton, 1997; McEnery and Kifle, 2002; Gabrielatos and McEnery, 2005; Biber, 2006). The present study concentrates on the use of epistemic verbs found in doctoral dissertations produced by native, Turkish-speaking and Spanish-speaking academic authors of English. It is intended to reveal whether these academic authors with different L1 backgrounds in English significantly differ from each other in certainty and likelihood expressions they use while conveying their stance to the readers.

\section{LITERATURE REVIEW}

Skelton (1988) contends that epistemic comments are widely used in the arts and sciences stressing they are found in one third or one half of the sentences. Ventola and Maureanen (1990) conducted a study with a focus on epistemic stance devices comparing Finnish-speaking learners of English and English native speakers and they concluded that the native group displayed more confidence using safe expressions of epistemic possibility in their writing. In a similar study, Gosden (1990) examined scientific research papers regarding modality markers and revealed that the markers which express writer's perception of uncertainty comprised an insignificant amount of the grammatical subjects used in the papers. Investigating MA dissertations produced in the scope of Linguistics and English Language, Gabrielatos and McEnery (2005) found that epistemic modals, 
epistemic adjectives and epistemic adverbs appeared more frequently in the dissertations of the native students than those written by the than non-native students. Kafes (2009) analysed research articles written by native and non-native speakers of English in terms of stance modals and reported an insignificant statistical difference between the groups concerning the use of the modals except may. In a corpus-based study on grammatical stance devices, Biber (2006) found that certainty verbs controlling that-clauses occur more common in the teacher-centred academic registers while the likelihood verbs controlling that-clauses appear more frequently in the student-centred academic registers. As noted in the previous section, our study focuses on the use of epistemic verbs, which are used to convey certainty and likelihood meanings, in doctoral dissertations of native and non-native academic authors of English. The following section will describe and outline research design adopted in the present study.

\section{RESEARCH DESIGN}

\subsection{Research questions}

This study primarily sought answers to the following research questions:

1. Do Turkish-speaking academic authors of English and native academic authors of English significantly differ with respect to epistemic verbs?

2. Do Spanish-speaking academic authors of English and native academic authors of English significantly differ with respect to epistemic verbs?

3. Do Turkish-speaking academic authors of English and Spanish-speaking academic authors of English significantly differ with respect to epistemic verbs?

\subsection{Methodology}

The present study employs a corpus-based approach to investigate author stance in doctoral dissertations of native and non-native academic authors of English. Throughout the study, epistemic verbs that are mostly found in written academic registers in Biber's study (2006) were searched across the dissertations in concern. Table 2displays them in two categories.

Table 2 Epistemic verbs (Adapted from Biber, 2006, p. 92)

\begin{tabular}{ll}
\hline Epistemic verbs & \\
\hline Certainty & $\begin{array}{l}\text { conclude, demonstrate, determine, discover, find, know, } \\
\text { learn, mean, notice, observe, prove, realize, recognize, } \\
\text { remember, see, show, understand } \\
\text { appear, assume, believe, doubt, gather, guess, happen, } \\
\text { hypothesize, imagine, predict, presuppose, presume, reckon, } \\
\text { seem, speculate, suppose, suspect, tend, think }\end{array}$ \\
\hline
\end{tabular}

\subsection{Data}

A few stages were followed in building data. Initially, doctoral dissertations produced by Turkish-speaking Academic Authors of English (TAEs, henceforth), Spanish- 
Speaking Academic Authors of English (SAEs, hereafter) and Native Academic Authors of English (NAEs, henceforth) within the field of English Language Teaching, English Language and Literature, Applied Linguistics and Modern Languages were collected by the researcher. For practical reasons, the corpora were constructed with the collection of dissertations available online. Thereby, three sets of corpora were built with a total number of 133 dissertations written between 2005 and 2012 [TACE (Turkish Academic Corpus of English): 48; SACE (Spanish Academic Corpus of English): 43; NACE (Native Academic Corpus of English): 45]. Secondly, the sections Abstract, Introduction, Review of Literature, Methodology and References were excluded from the corpora. The analysis was performed through the sections Findings, Discussion, Conclusion, Pedagogical Implications (Implications to English Language Teaching) and Suggestions for Further Research of the doctoral dissertations. Lastly, all figures, paraphrases, quotations, tables, titles and subtitles were excluded from the above-mentioned sections of the dissertations in the corpora. Table 3 illustrates the size of each corpus.

Table 3 Corpus size

\begin{tabular}{lcc}
\hline Corpus & Dissertations $(\mathrm{N})$ & Size (word number) \\
\hline TACE & 48 & 675.072 \\
SACE & 45 & 668.256 \\
NACE & 43 & 671.475 \\
Total & 136 & 2.014 .873 \\
\hline
\end{tabular}

\subsection{Data analysis}

Contrastive Interlanguage Analysis (CIA) (Granger, 1996) was practically used in data analysis which comprised of six stages. In the first three stages, each set of corpus was examined in its own right with respect to the epistemic verbs identified in the previous section. Subsequently, the non-native corpora were compared with the native corpus in terms of these items. Finally, TACE and SACE were compared regarding the items in question.

The first three stages of data analysis required using Wordsmith Tools 6.0, a computer software package developed (Scott, 2012), "for analysing the lexis of texts and corpora in order to produce frequency lists, to run concordance searches and calculate collocations for particular words, and to find keywords in a text and examine their distribution" (cited in Baker et al. 2006 p. 169) to count frequencies of each item in three corpora. It is noteworthy that certain items, which were likely to be confused with epistemic nouns, were distinctively analysed in order to avoid ambiguous results (e.g., doubt, result and claim). It should also be noted that all items were searched in present, progressive, past and participle forms (e.g., see, sees, seeing, saw, and seen). Finally, the items with different spellings across the forms of English were carefully investigated throughout the procedure (e.g. analyse in BrE and analyze in AmE). For the last three stages, Log Likelihood Statistics, which was previously used in significant studies carried out in the field of corpus linguistics (e.g. Granger and Rayson, 1998; Scott, 2011), was employed to make comparison among three sets of data concerning the observed and expected values for the items. 


\section{RESULTS AND DISCUSSIONS}

This section offers findings obtained from the analysis of three corpora including doctoral dissertations produced by TAEs, SAEs and NAEs. Following Biber (2006), a total number of 36 English epistemic verbs were identified over three corpora (under two main categories as certainty verbs and likelihood verbs)and their frequencies were calculated via WS Tools 6.0. Then, the corpora were administered an analysis for categorical and individual epistemic verbs to see whether native and non-native authors of English significantly differ from each other with respect to the use of these items. Nevertheless, it might be useful to display epistemic verbs not found in three corpora:

e.g. I gather from your letter [that you're not enjoying your job].

I reckon [(that) I am going to get that job].

(Oxford Advanced Learner's Dictionary, 2010)

\subsection{Epistemic verbs in three corpora}

Three corpora were compared regarding the use of 36 epistemic verbs proposed by Biber (2006). 33 out of 36 types were used in SACE, which corresponds to the highest frequency in all corpora, whereas 32 types were found in NACE and 30 in TACE. In accordance with the findings, epistemic verbs were mostly used in TACE (2920 times) while they appeared 2360 and 2022 times in NACE and SACE, respectively. Likewise, the frequency analysis has indicated that epistemic verbs were overused by TAEs and underused by SAEs in comparison with NAEs, which is illustrated in Table 4.

Table 4 Overall frequency distribution of epistemic verbs in three corpora

\begin{tabular}{lccc}
\hline & NACE (L1) & TACE (L2) & SACE (L2) \\
\hline Corpus size in words & 671.475 & 675.072 & 668.256 \\
Epistemic verb (n) & 2360 & 2920 & 2022 \\
n per 10.000 & 35.15 & 43.25 & 30.26 \\
T/t ratio (\%) & 0.04 & 0.04 & 0.03 \\
Epistemic verb types (n) & 32 & 30 & 33 \\
\hline \multicolumn{4}{c}{ T/t ratio= Type/token ratio; percentage of number of epistemic verbs (types) } \\
& in total of words (tokens) in each corpus
\end{tabular}

As presented in Table 4, the lowest frequency was observed in SACE and the highest frequency in TACE, which entails there is an underuse in the dissertations produced by SAEs (2022 times) and an overuse in those written by TAEs against NACE in terms of epistemic verbs. The frequency ratio of epistemic verbs in NACE was measured 35.15 per 10.000 words; in other words, these items were used over 35 times in every 10.000 words in NACE. They were seen over 43 and 30 times in every 10.000 words in TACE and SACE, respectively. It is essential to utilize statistics to investigate whether the values of overuse and underuse in the non-native corpora against the native corpus are significant. Initially, overall frequencies of epistemic verbs in three corpora were counted and LL ratio was calculated to make comparisons across them regarding epistemic verbs. The first LL analysis was performed to reveal whether there is a statistically significant 
difference between TACE and NACE in terms of epistemic verbs. Table 5 shows the related results.

Table 5 LL ratio of epistemic verbs in TACE and NACE

\begin{tabular}{cccc}
\hline & TACE & NACE & LL ratio \\
& $\mathrm{N}$ & $\mathrm{n}$ & $(* \mathrm{p}<0.05)$ \\
\hline Epistemic verbs & 2920 & 2360 & +56.55 \\
\hline & $\mathrm{n}=$ raw frequency of epistemic verbs in corpus & \\
& + indicates overuse in TACE relative to NACE & \\
& - indicates underuse in TACE relative to NACE
\end{tabular}

The results have indicated a statistically significant difference between TACE and NACE with respect to frequency of epistemic verbs $(\mathrm{p}<0.05)$. Then, SACE and NACE were compared regarding the overall frequency of the items, as outlined in Table 6.

Table 6 LL Ratio of epistemic verbs in SACE and NACE

\begin{tabular}{lccc}
\hline & SACE & NACE & LL ratio \\
& $\mathrm{N}$ & $\mathrm{n}$ & $(* \mathrm{p}<0.05)$ \\
\hline Epistemic verbs & 2022 & 2360 & -24.50 \\
\hline & $\mathrm{n}=$ raw frequency of epistemic verbs in corpus \\
& + indicates overuse in SACE relative to NACE & \\
& - indicates underuse in SACE relative to NACE
\end{tabular}

As illustrated in Table 6, the underuse in SACE against NACE was approved by LL results with a value of +24.50 . Lastly, TACE and SACE were compared in order to see whether they significantly differ with respect to the use of epistemic verbs. The test results are provided in Table 7.

Table 7 LL Ratio of epistemic verbs in TACE and SACE

\begin{tabular}{lccc}
\hline & TACE & SACE & LL Ratio \\
& $\mathrm{N}$ & $\mathrm{n}$ & $(* \mathrm{p}<0.05)$ \\
\hline Epistemic verbs & 2920 & 2022 & +155.10 \\
\hline & $\mathrm{n}=$ raw frequency of epistemic verbs in corpus \\
& + indicates overuse in TACE relative to SACE & \\
& - indicates underuse in TACE relative to SACE
\end{tabular}

It is seen that epistemic verbs were used in TACE much more frequently than SACE, which was approved by a $+155.10 \mathrm{LL}$ value. Hitherto, frequency categories of epistemic verbs across three corpora as well as the LL results obtained from the analyses of the native and non-native corpora have been presented. As this is not considered adequate to account for whether these devices tend to convey the meaning of "certainty" or "likelihood" throughout the works they appeared, as a further analysis, the non-native corpora were individually compared with the native corpus and with each other with regard to certainty and likelihood verbs. 


\subsubsection{Certainty and likelihood verbs in three corpora}

This section presents the results of the analysis administered to three corpora to investigate whether they significantly differ in the use of certainty and likelihood verbs. Figure 1 demonstrates the related results.

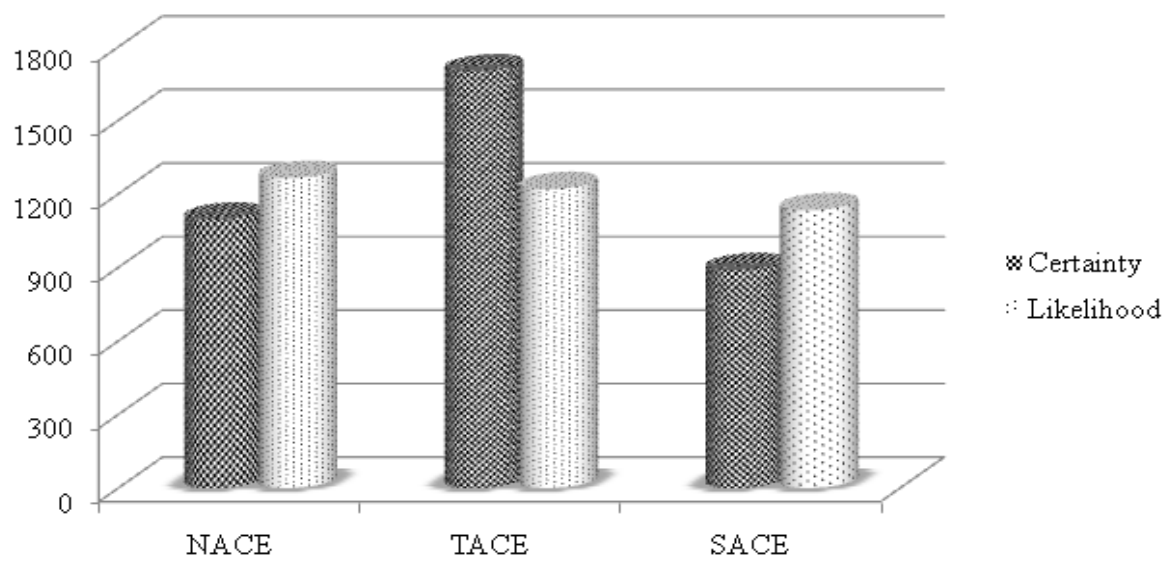

Fig. 1 Distribution of certainty and likelihood verbs in three corpora

As suggested in Figure 1, TACE revealed to be only corpus where certainty verbs occurred more frequently than likelihood verbs. However, three corpora relatively differ from each other in the use of certainty and likelihood items. Certainty verbs appeared most frequently in TACE and least frequently in SACE, which leads us to the conclusion that they were overused by TAEs and underused by SAEs against the native group. Likelihood verbs, on the other hand, were most frequented in NACE (1265 times). They were slightly less frequented in the non-native corpora.

The most frequently used certainty verb across three corpora is show, which appeared 616 times in TACE, 502 times in NACE and 314 times in SACE. It is noteworthy that show constitutes approximately $50 \%$ of the certainty verbs in NACE, $36 \%$ in TACE and $35 \%$ in SACE. The following statements are taken from each corpus to exemplify the item in concern.

e.g. [Overall, the spoken narrative results have shown that more than any other tense English and German low group learners use the PC in perfective contexts.]

Extracted from <NACE-UE-2008-FCK >

[The results of the ANOVA analysis showed that there was a significant difference among the level of anxiety of student teachers from different departments.]

Extracted from <TACE-AU-2010-MA>

[There is a growing body of research in cognitive psychology showing that mental representations of perceptual experience are central to cognition.]

Extracted from SACE-UG-2011-JMUG> 
Since certainty verbs in three corpora mostly comprised of only one type, it might be practical to use another figure to provide a clearer picture of the other certainty verb types found across the corpora in concern. Figure 2 illustrates the frequency distribution of the individual certainty verbs except show in three corpora.

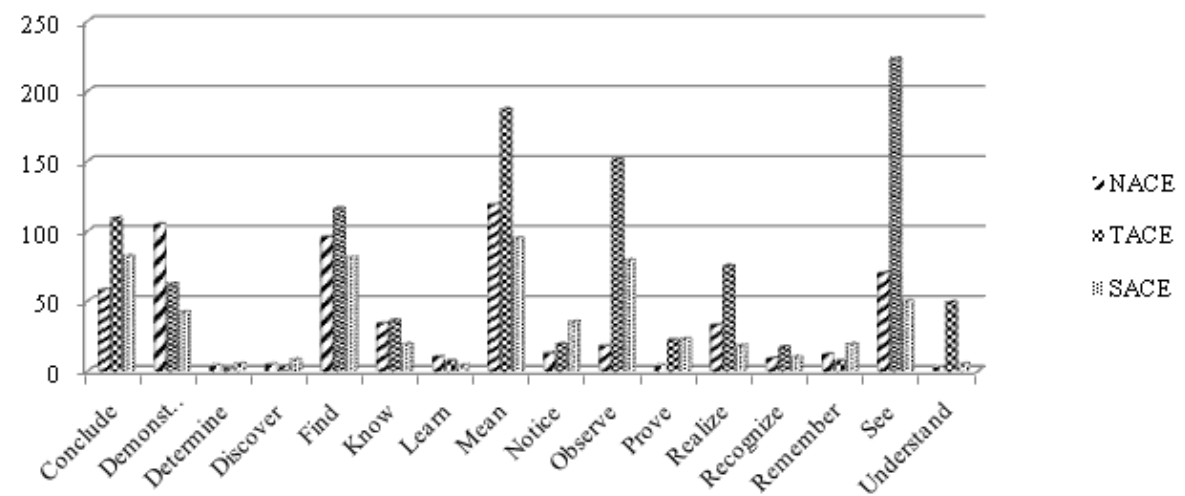

Fig. 2 Certainty verbs excluding show in three corpora

Being the second most frequented certainty verb following show in both NACE and SACE, mean was the third most frequently used item in TACE. See, on the other hand, was mostly preferred by TAEs with a frequency of 223 while it was used 70 and 50 times by NAEs and SAEs, respectively. Demonstrate was used by NAEs much more frequently than both non-native groups.

Likelihood verbs were mostly found in NACE, corresponding to the fact that they were underused by both non-native groups in comparison to the native group.

Similar to the case for certainty verbs, not a balanced distribution was observed concerning the use of likelihood verbs in three corpora. Seem revealed the mostly used likelihood verb in three corpora. It was mostly preferred by SAEs (646 times) while it was used by TAEs and NAEs relatively less often (549 times and 488 times, respectively). The followings are extracted from each corpus to illustrate the item in concern.

e.g. [During the time they are supposed to be describing the worst day of their life, they don't seem to be understanding what they're doing.]

Extracted from $<$ NACE-UI-2012-EJE $>$

[At a time when color-blind ethics seemed to be the norm in 1990s middle-class America, race continued to be ardently discussed in the jazz sphere.]

Extracted from SACE-UCM-2012-CAR>

[The results seem to reveal that Turkish EFL learners have somesort of sensitivity to some situational factors when requesting in English.]

Extracted from <TACE-AU-2008-AZG>

As in the case of certainty verbs, it is considered useful to illustrate likelihood verbs excluding seem to get a better understanding into their distribution across three corpora. Figure 3 offers the distribution in question. 


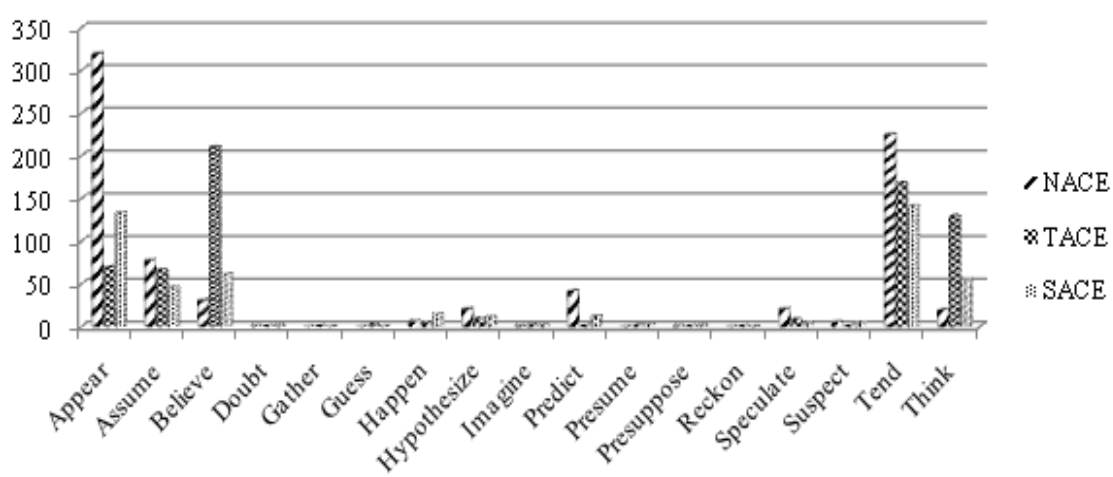

Fig. 3 Likelihood verbs excluding seem in three corpora

Three corpora seem to differ from each other in the distribution of most likelihood verbs. As a matter of fact, they bear similarities only in the use of the least frequented items such as doubt, imagine, presume and presuppose. An interesting finding of the study might be that the likelihood verb appear was extensively used in the native corpus while it was found much less frequently in the non-native corpora. Another interesting finding might have to do with the use of believe and think. Namely, they revealed among the mostly used likelihood verbs in TACE whereas they were used relatively less frequently in both NACE and SACE.

Finally, a log likelihood test was run to three corpora to find out whether the underuse values found in non-native corpora against the native corpus are statistically significant and whether there is a statistically significant difference between TACE and SACE regarding the categories of epistemic verbs. The first test was administered to TACE and NACE and the related results are shown in Table 8.

Table 8 LL ratio of certainty and likelihood verbs in TACE and NACE

\begin{tabular}{lccc}
\hline Epistemic verbs & TACE & NACE & LL ratio \\
& $\mathrm{N}$ & $\mathrm{n}$ & $\left({ }^{*} \mathrm{p}<0.05\right)$ \\
\hline Certainty verbs & 1700 & 1095 & +128.79 \\
Likelihood verbs & 1220 & 1265 & -1.07 \\
\hline
\end{tabular}

$\mathrm{n}=$ raw frequency of epistemic verbs in corpus

+ indicates overuse in TACE relative to NACE

- indicates underuse in TACE relative to NACE

As can be seen in Table 8, certainty verbs were significantly overused in TACE against NACE, which was confirmed with a +128.79LL value. Likelihood verbs, on the other hand, reveal to be slightly underused in TACE. Namely, they occurred 1220 times in TACE while they were seen 1265 times in NACE. It was again approved by LL results (-1.07 LL value). The results of the analysis made between SACE and NACE are shown in Table 9. 
Table 9 LL ratio of certainty and likelihood verbs in SACE and NACE

\begin{tabular}{lccc}
\hline Epistemic Verbs & SACE & NACE & LL ratio \\
& $\mathrm{N}$ & $\mathrm{n}$ & $\left({ }^{\mathrm{p}}<0.05\right)$ \\
\hline Certainty verbs & 889 & 1095 & -20.45 \\
Likelihood verbs & 1134 & 1265 & -6.54 \\
\hline
\end{tabular}

$\mathrm{n}=$ raw frequency of epistemic verbs in corpus

+ indicates overuse in SACE relative to NACE

- indicates underuse in SACE relative to NACE

Table 9 suggests that both certainty and likelihood verbs were underused in SACE against NACE and these findings were approved by LL results. The results of the test administered to TACE and SACE are displayed in Table 10.

Table 10 LL ratio of certainty and likelihood verbs in TACE and SACE

\begin{tabular}{lccc}
\hline Epistemic Verbs & TACE & SACE & LL ratio \\
& $\mathrm{N}$ & $\mathrm{n}$ & $\left({ }^{*} \mathrm{p}<0.05\right)$ \\
\hline Certainty verbs & 1700 & 889 & +250.21 \\
Likelihood verbs & 1220 & 1134 & +2.33 \\
\hline \multicolumn{4}{c}{ n=raw frequency of epistemic verbs in corpus } \\
& + indicates overuse in TACE relative to SACE \\
& - indicates underuse in TACE relative to SACE
\end{tabular}

Table 10 clearly shows that both certainty and likelihood verbs were significantly overused in TACE against SACE. Namely, certainty verbs were preferred 1700 times by TAEs while they were used 889 times by SAEs. In a similar vein, likelihood verbs occurred 1220 times in TACE whereas they were found 1134 times in SACE. Both results were confirmed by LL results $(\mathrm{p}<0.05)$.

\section{CONCLUSION}

In this particular study, epistemic verbs in doctoral dissertations written by TAEs (Turkish-Speaking Academic Authors of English), NAEs (Native Academic Authors of English) and SAEs (Spanish-speaking Academic Authors of English) were analysed through the quantitative analysis method. Largely, it has been found that 2 out of 36 types were not found in any corpora. This section presents the evaluation of research questions, implications to language teaching and a couple of suggestions for further research.

\subsection{Evaluation of research questions}

The first research question of the study was posed to reveal whether TAEs and NAEs significantly differ with respect to the use of epistemic verbs. The findings have shown that TAEs used epistemic verbs in their dissertations much more frequently than NAEs, which was confirmed with the results of statistical analysis $(\mathrm{p}<0.05)$. As for the categories of epistemic verbs, a significant overuse was observed in TACE against NACE regarding the use of certainty verbs, while an underuse was found in TACE against NACE in that of likelihood verbs, which was also approved by statistical results. That is, TAEs are more 
confident with their predictions, while NAEs are more tentative in expressing themselves while writing academically.

The second question was intended to find out whether SAEs and NAEs significantly differ in terms of epistemic verbs. It has been observed that both certainty and likelihood verbs were employed less frequently in SACE than in NACE, which indicates an underuse in SACE against NACE in the categories in concern. The statistical results have approved both findings. On the contrary to the case between TAEs and NAEs, SAEs have proved more cautious in their writing when compared to the native group.

The third question investigated whether TAEs and SAEs significantly differ concerning the use of epistemic verbs. As in the case between TACE and NACE, it has been revealed that both certainty and likelihood verbs were notably more frequented in TACE than in SACE, which was approved by a statistically significant difference between TAEs and SAEs with regard to the use of these verbs. As a natural outcome of the above-mentioned two findings, TAEs tend to use more confident expressions while SAEs prefer likelihood ones in their academic writing.

Considering the fact that all sets of corpora investigated in the study included doctoral dissertations of advanced learners of English, one cannot attribute the findings to the proficiency level of the writers. They, rather, might have to do with cultural differences or thought patterns between the community they were born and raised and the one of which spoken language they have learned as a second/ foreign language.

\subsection{Implications to language teaching}

While there is clear pedagogical justification for assisting learners to develop an awareness of the significance hedging and the principles of its correct use, tentative language continues to be an important source of pragmatic failure in the writing of second language science students (Hyland, 1994, p. 239).This particular finding reported by Hyland here cannot be confined to the analysis of papers written by science students; that is, it has also been obtained from other research conducted on such kind of papers produced by students studying social sciences. Namely, our study has indicated that TAEs are more confident with their predictions whereas the other two groups are inclined to use more tentative expressions in their writing. This might be attributed to the fact that dissertations investigated in this study might have been written by students who had never taken a course such as academic writing as it is not offered as a compulsory part of curriculum in most of the graduate programmes in Turkey. So, it might be suggested that academic writing be included into the curricula of these programmes as a compulsory course whereby principles of writing scientific papers could be presented in detail and the students should be expected to pass the course in concern prior to writing their dissertations.

\subsection{Suggestions for further research}

The present study is limited to the investigation of doctoral dissertations written by Turkish-speaking, Spanish-speaking and native academic authors of English between 2005 and 2012. It is also limited to the field of English Language Teaching, English Language and Literature, Applied Linguistics and Modern Languages. In order to attain more generalizable results, further research might involve investigating broader corpora thatcomprise spoken and/or writtenproductionsof non-native academic authors of English and that are produced inother disciplines. 


\section{REFERENCES}

Costas Gabrielatos and Tony McEnery, Epistemic modality in MA dissertations, in Lengua y Sociedad: Investigacion e srecientes en linguistic aplicada, ed. Fuertes Olivera, 311-331. Lingüística y Filología, 61. Valladolid: Universidad de Valladolid, 2005.

Douglas Biber, and Edward Finegan. "Styles of stance in English: Lexical and grammatical marking of evidentiality and affect". Text9 (1989): 93-124.

Douglas Biber, University language: A corpus-based study of spoken and written registers. Amsterdam: John Benjamins, 2006.

Eija Ventola and Anna Maureanen, Research and Writing in English. Helsinki: Yliopistopaino, 1990.

Françoise Salager-Meyer, "I Think that Perhaps You Should: A Study of Hedges in Written Scientific Discourse", in Functional Approaches to Written Text: Classroom Applications, ed. Tom Miller, 105-118.English Language Programs: United States Information Agency, 1997.

Hugh Gosden. "Discourse functions of subject in scientific research articles". Applied Linguistics, 14(1) (1990): 56-75.

Hüseyin Kafes, (2009). Authorial stance in academic English: Native and non-native academic speaker writers' use of stance devices (modal verbs) in research articles. $\mathrm{PhD}$ Thesis, Anadolu University.

John Skelton, "Comments in academic articles", in Applied Linguistics in Society: British Studies in Applied Linguistics 3, ed. Pamela Grunwell, 98-108. London: Centre for International Language, 1988.

Ken Hyland, "Hedging in Academic Writing and EAP Textbooks". English for Specific Purposes, 13(3) (1994): 239-256.

Michael Stubbs, “A matter of prolonged field work: notes toward a model grammar of English". Applied Linguistics, 7(1) (1986): 1-25.

Mike Scott, Word Smith Tools version 6. Liverpool: Lexical Analysis Software, 2012.

Oxford advanced learner's dictionary. Oxford: Oxford University Press, 2000.

Paul Baker, Andrew Hardie, and Tony McEnery, A glossary of corpus linguistics. Edinburg: Edinburg, 2006.

Susan Conrad and Douglas Biber, "Adverbial Marking of Stance in Speech and Writing", in Evaluation in Text. Authorial Stance and the Construction of Discourse, eds. Susan Hunston and Geoff Thompson, 56-73. Oxford Linguistics: Oxford.

Susan Hunston and Geoff Thompson, "Evaluation: Anintroduction", in Evaluationin text: authorial stance and the construction of discourse, eds. Susan Hunston and Geoff Thompson. Oxford: Oxford University Press 2000.

Sylviane Granger, "From CA to CIA and back: An integrated approach to computerized bilingual and learner corpora", in Languages in contrast, ed. Karin Aijmer, Bengt Altenberg, and Mats Johansson, 37-51. Lund: Lund University Press, 1996. 